\title{
Syringomyelia Associated with Spinal Dural Arteriovenous Fistula: Clinical and Radiological Improvement after Embolization
}

\author{
Rakesh Singh, DM ${ }^{1}$, Narayan Deshmukh, $\mathrm{DM}^{1}$, Rakesh Lalla, $\mathrm{DM}^{2}$, Satish Khadilkar, $\mathrm{DM}^{1}$ \\ ${ }^{1}$ Department of Neurology, Bombay Hospital and Medical Research Centre, Mumbai, India \\ ${ }^{2}$ Department of Neurology, Fortis Hospital, Kalyan, Kalyan, India
}

Spinal dural arteriovenous fistulae (AVF) are rare and can result in spinal cord dysfunction. We present one such case wherein the patient presented with a venous congestive myelopathy. Magnetic resonance imaging showed a syrinx formation, spinal cord edema, and flow voids. Digital subtraction angiography confirmed the dural AVF, which was treated with embolization. The syrinx disappeared, other spinal cord changes improved, and the patient had remarkable clinical improvement. The case is presented to draw attention to the rare formation of a syrinx in a spinal dural arteriovenous fistula and its disappearance after successful embolization.

Key Words: Spinal dural arteriovenous fistula; Syringomyelia; Embolization; Spinal cord edema; Flow voids

\section{INTRODUCTION}

Spinal dural arteriovenous fistula (AVF) is a rare condition. ${ }^{1}$ Patients having a dural AVF present with a wide variety of symptoms and can pose diagnostic challenges. Syringomyelia secondary to a dural AVF is an extremely uncommon presentation of a dural AVF, and limited literature is available on the clinical course and therapy responses of such patients. We present a patient with venous congestive myelopathy associated with syringomyelia in the thoracic spinal cord who showed improvement after successful embolization.

\section{CASE REPORT}

A 45-year-old male presented with insidious onset, gradually progressive weakness of the legs causing difficulty in walking for 6 months. He did not have fever or trauma at the onset. Three weeks before presentation, his symptoms worsened, he lost control over bladder and bowel, and became bedridden. He had paresthesiae in both legs, but neither girdle sensation nor sensory level was noticed. There were no motor or sensory complaints about his arms. His examination revealed normal cranial nerve function, and upper limbs were normal to examination. There was no dissociative sensory loss. He was diagnosed to have longitudinal-

\section{Correspondence to:}

Satish Khadilkar, DM

Department of Neurology, Bombay

Hospital and Medical Research Centre, New Marine Lines, Mumbai, Maha-

rashtra-400020, India

Tel: $+91-2222072489$

Fax: +91-2208087

E-mail: khadilkarsatish@gmail.com

Received: May 19, 2020

Revised: August 19, 2020

Accepted: August 21, 2020

Copyright $\odot 2020$ Korean Society of Interventional Neuroradiology

This is an Open Access article distributed under the terms of the Creative Commons Attribution Non-Commercial License (http://creativecommons.org/licenses/by-nc/4.0) which permits unrestricted non-commercial use, distribution, and reproduction in any medium, provided the original work is properly cited.

pISSN 2093-9043 eISSN 2233-6273 
ly extensive transverse myelitis based on the interpretation of contrast-enhanced magnetic resonance imaging (MRI) of the dorso-lumbar spine and received corticosteroids. His disability score was 5 (confined to a wheelchair) on the modified Aminoff-Logue Disability Scale for gait (AL-G) and 3 (total incontinence) on the modified Aminoff-Logue Disability Scale for micturition. The PSMS (pain, sensory, motor, and sphincter) grading system for venous congestive myelopathy score was POS1M3S3 (no pain, mild sensory symptoms, confined to wheelchair, persistent incontinence). ${ }^{2}$ He was referred to our institute following a worsening of symptoms after transient improvement.

Serological investigations, including complete blood counts, electrolytes, a human immunodeficiency virus test, and vitamin B12 levels, were within normal ranges. A review of his spine MRI revealed a T2 and Flair hyperintensity extending from the lower dorsal cord (T7) to the lumbar cord (L1) with syrinx formation in the lower dorsal cord from T6 to T8 (Fig. 1A, B). There were multiple flow voids around the swollen thoracic spinal cord due to venous congestive myelopathy (Fig. 1B, arrowheads). These flow voids on T2 sequences raised the suspicion of a spinal dural AVF. Spinal dig-
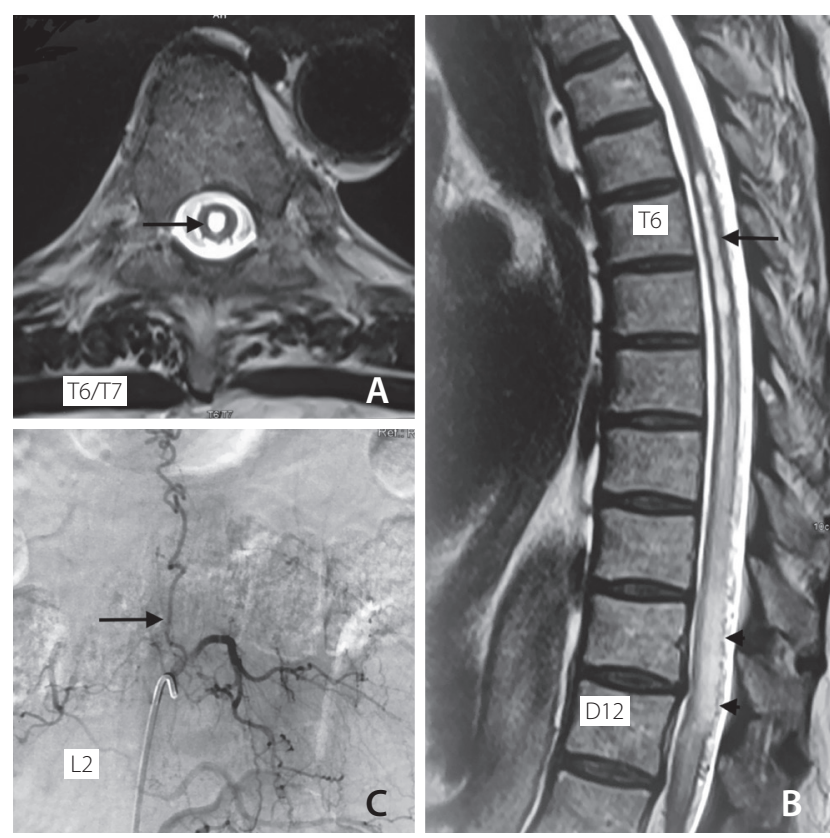

Fig. 1. Pre embolization status showing (A) T2-weighted axial section of cord at T6/T7 level showing syrinx (arrow), (B) T2 weighted sagittal section of spinal cord showing syrinx from upper border of T6 to T8 (arrow) and hyperintense signal from T7 to L1 with flow-voids from T10 to T12 (arrowheads), (C) DSA at L2 level showing dural AV fistula (arrow) with draining vein reaching up to thoracic level. DSA, digital subtraction angiography; $\mathrm{AV}$, arteriovenous. ital subtraction angiography (DSA) confirmed the presence of a dural AVF. DSA showed the fistula to be at the L2 level with venous filling up to the upper thoracic cord (Fig. 1C).

The dural AVF was embolized with the non-adhesive liquid embolic agent Onyx ${ }^{\top M}$ (ethylene vinyl alcohol copolymer dissolved in dimethyl sulfoxide) (Micro Therapeutics Inc., Irvine, CA, USA) (Fig. 2C). A Marathon microcatheter (Micro Therapeutics Inc.) was navigated over a Mirage 0.008 wire (Micro Therapeutics Inc.) in the dural branch of left L2. Onyx18 was injected over 15 minutes to obliterate the feeders and the fistula site. An Onyx cast was well-visualized following successful embolization (Fig. 2D). He improved as examined on follow-up visits, and could walk without assistance with minimal urinary complaints over the next 4 weeks. His post-operative disability score was 1 (leg weakness but no restriction of activity) on the modified AL-G and 1 (hesitancy and urgency) on the modified Aminoff-Logue Disability Scale for micturition. The PSMS grading system score was POSOM1S1 (no pain, no sensory symptoms, leg weakness, difficult voiding). ${ }^{2}$ Follow-up contrast-enhanced MRI of the spine performed 6 months after the procedure showed resolution of the syrinx, disappearance of flow voids, and

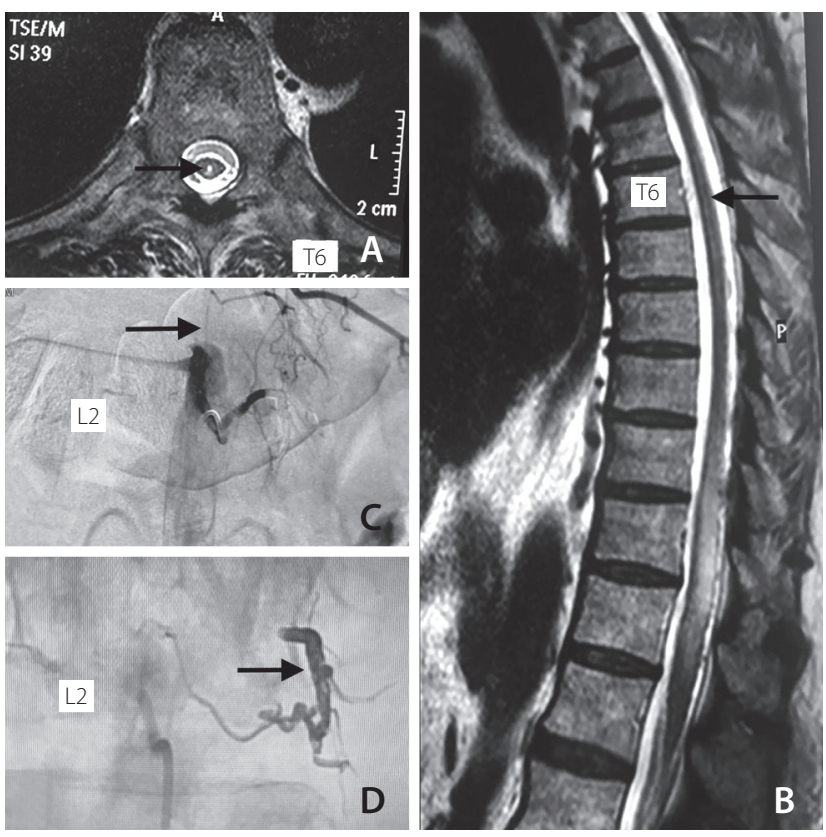

Fig. 2. Post embolization status showing (A) T2 weighted axial image of cord at T6 level showing reduction in syrinx size (arrow), (B) T2 weighted sagittal cord image showing reduction in hyperintense signal, syrinx size (arrow), and disappearance of flow voids, (C) DSA at L2 level showing successful embolization of dural AV fistula (arrow), (D) Onyx cast post embolization of fistula (arrow). DSA, digital subtraction angiography; $\mathrm{AV}$, arteriovenous. 
reduction of T2/Flair hyperintense signal, proving successful embolization of the dural AVF (Fig. 2A, B).

\section{DISCUSSION}

We presented a rare case of a spinal dural AVF with venous congestive myelopathy as well as syringomyelia.

A spinal dural AVF is abnormal communication between arteries and veins that results in arterialization of radicular veins.' A spinal dural AVF leads to venous hypertension and stasis of blood flow. Resultant congestion causes vasogenic edema in the spinal cord. The clinical presentation and imaging features mimic non-compressive myelopathy like transverse myelitis. Since a dural AVF is rare and is easily missed if one doesn't look for flow voids specifically, there is a chance of error or delay in diagnosis as well as treatment. ${ }^{3}$

In the present case, MRI of the spine showed syringomyelia. A syrinx is a fluid-filled cavity in the spinal cord. There are many theories regarding the pathophysiology of primary syringomyelia; amongst the frequently cited are those of Gardner, ${ }^{4}$ William, ${ }^{5}$ and Oldfield et al. ${ }^{6}$. The exact mechanism of syrinx formation in a case of a spinal dural AVF is unclear but can be related to venous hypertension and congestion. It is postulated that development of a spinal syrinx begins with obstruction of cerebrospinal fluid (CSF) within the spinal subarachnoid space (SAS). Obstruction of the SAS dampens the ability to counter subarachnoid CSF pressure waves that are generated with every heartbeat. This results in a generation of waves of greater amplitude than normal. These waves drive the CSF in the spinal cord, cause edema, and later lead to the formation of a syrinx. ${ }^{7}$ A syrinx develops at a higher level above the site of a dural AVF, as was seen in the present case. Hence doing a complete spinal DSA, including both internal iliac arteries, is mandatory to avoid missing a lumbosacral dural AVF.

In the present case, the dural AVF caused venous congestion, resulting in edema in the long segment of the spinal cord, causing a syrinx (T6-T8) at a level above the fistula site (L2). Thus, the syrinx resolved after successful embolization and did not recur. There was significant clinical improvement in motor and sensory deficits. The spinal cord edema below the level of the syringomyelia and dural AVF was predominantly responsible for clinical symptoms in this case.

Long-term prognosis depends on early diagnosis and treatment of such a dural AVF. Brinjikji and colleagues ${ }^{8}$ showed that a mean delay of 6 months or more in the treatment of a dural AVF was associated with poor outcomes. However, treatment at later stages may also provide optimistic results, as was seen in the case presented in this report, as the patient showed excellent recovery despite being symptomatic for about 6 months. Case reports of successful treatment of a syrinx due to a dural AVF are scarce in the literature. ${ }^{9}$ Zaed and colleagues ${ }^{10}$ showed resolution of a syrinx due to a dural AVF by surgical ligation.

\section{Fund}

None.

\section{Ethics Statement}

As this is part of standard of care treatment, IRB was not approached.

\section{Conflicts of Interest}

The authors have no conflicts to disclose.

\section{Author Contributions}

Concept and design: RS and SK. Analysis and interpretation: RS, ND, and RL. Data collection: RS, ND, RL, and SK. Writing the article: $R S, N D, R L$, and SK. Critical revision of the article: $R S, N D, R L$, and SK. Final approval of the article: $R S, N D, R L$, and SK. Overall responsibility: RS and SK.

\section{ORCID}

Rakesh Singh: https://orcid.org/0000-0001-9308-3543

Narayan Deshmukh: https://orcid.org/0000-0002-9219-453X

Rakesh Lalla: https://orcid.org/0000-0001-8689-7960

Satish Khadilkar: https://orcid.org/0000-0001-9431-3179

\section{REFERENCES}

1. Kramer CL. Vascular disorders of the spinal cord. Continuum (Minneap Minn) 2018;24:407-426

2. Suh DC, Song Y, Park D, et al. New grading system for the clinical evaluation of patients with spinal vascular lesions. Neuroradiology 2018;60:1035-1041

3. Hunt R, Roberts RM, Mortimer AM. Spinal dural arteriovenous fistula: delay to radiological diagnosis and sources of radiological error. Clin Radiol 2018;73:835.e11-835.e16

4. Gardner WJ. Hydrodynamic mechanism of syringomyelia: its relationship to myelocele. J Neurol Neurosurg Psychiatry 
$1965 ; 28: 247-259$

5. Williams B. Progress in syringomyelia. Neurol Res 1986;8:130-145

6. Oldfield EH, Muraszko K, Shawker TH, Patronas NJ. Pathophysiology of syringomyelia associated with Chiari I malformation of the cerebellar tonsils. Implications for diagnosis and treatment. J Neurosurg 1994;80:3-15

7. Heiss JD, Snyder K, Peterson MM, et al. Pathophysiology of primary spinal syringomyelia. J Neurosurg Spine 2012;17:367-380

8. Brinjikji W, Nasr DM, Morris JM, Rabinstein AA, Lanzino G. Clini- cal outcomes of patients with delayed diagnosis of spinal dural arteriovenous fistulas. AJNR Am J Neuroradiol 2016;37:380-386

9. Finsterer J, Bavinzski G, Ungersböck K. Spinal dural arteriovenous fistula associated with syringomyelia. J Neuroradiol 2000;27:211-214

10. Zaed I, Pinto MV, Mauermann ML, Lanzino G. Teaching neuroimages: spinal cord syrinx secondary to a spinal dural arteriovenous fistula. Neurology 2018;91:e295-e296 